\title{
CLINICAL AND RADIOGRAPHIC EVALUATION OF MARGINAL BONE STATUS AROUND TWO DIFFERENT TYPES OF DENTAL IMPLANTS
}

\author{
Hamdy A Abou Elkhair* Abdel-Fattah M Amer** and Akram A El Awady ${ }^{* * *}$
}

\begin{abstract}
The aim of the study was to evaluate the marginal bone status around two types of implant abutment junction, which are platform switched and non-platform switched types using cone beam CT. 8 patients, 4 males and 4 females with an average age 32 year (range from 22 to 43 years), with posterior edentulous area of the mandible were included in this study. A thorough preoperative assessment of all patients was carried out including history taking, clinical examination including plaque and gingival index and radiographic examination. Study casts were created for evaluation of edentulous areas and occlusion, cone beam computed tomography(CBCT) scans were used as the final investigation, it was possible to correctly assess the width of each implant site, the thickness and density of the cortical plates and the cancellous bone, as well as the ridge angulation and a virtual implant treatment plane was performed. The implants used in this study were $3.4 \mathrm{~mm}$ in diameter, Submerged superline fixtures with dual abutments and non-submerged tissue level simple line implants with dual abutments (Dentium Co., Ltd., Gangnam-gu, Seoul, Korea). Implant insertion was performed according to manufacturer's instructions. Non submerged installation procedures were performed. Para crestal incisions with releasing incisions were done at surgical sites and Full-thickness flaps were reflected exposing the alveolar ridge, Sequential drills were used until the 3.4 diameter final drill under constant irrigation. Abutments were installed at time of surgery, and flaps were closed by interrupted sutures using 3"0" silk. At 2 months, a definitive abutment level impression was made and Acrylic restorations were cemented to the abutments. Modified plaque index (mPII) and modified Sulcus Bleeding Index ( $\mathrm{mBI}$ ) was carried out was carried out. Cone beam computed tomography (CBCT) has been carried out to evaluate buccal and lingual crestal bone changes. All radiographs for each case were taken under constant conditions. CBCT scans were carried out at baseline and 9 months post-surgically. The Comparison between the two groups showed no statistically significant difference between amounts of crestal bone loss in the two groups after 9 months.
\end{abstract}

\section{INTRODUCTION}

Dental implants have been considered as one of the most important innovations in the contemporary dentistry. Since the introduction of titanium implants for an intra-oral use in the late 1950s, dental implantology has an active as well as promising option for the oral rehabilitation of partially dentate or edentulous patients ${ }^{(1)}$. It is of value to note that clinical case studies ${ }^{(2-4)}$ and retrospective studies ${ }^{(5,6)}$ applying platform- switching indicated a lower rate of bone loss around these dental implants compared with implants received prosthetic abutments of the same diameter platform. The platformswitching (PS) concept is based on the use of an abutment smaller than the implant neck ${ }^{(7)}$. This type of connection moves the perimeter of implant abutment junction (IAJ) to implant axis center ${ }^{(8-10)}$. Moving the IAJ inward brings out bacteria more internally and, therefore, away from bone crest ${ }^{(11)}$. This technique has an important biomechanical advantages ${ }^{(12)}$, as the use of a narrow abutment in a PS configuration may shift the stress concentration away from peri- implant marginal bone, thus decreasing its bone resorptive effect ${ }^{(9,13)}$.

\footnotetext{
* BDS, Demonstrator, Faculty of Dental Medicine, Department of Periodontology, Al Azhar University, Cairo, Egypt ** Professor, Faculty of Dental Medicine, Department of Periodontology, Al Azhar University, Cairo, Egypt.

*** Professor, Faculty of Dental Medicine, Department of Periodontology, Al Azhar University, Cairo, Egypt.
} 
In dental implant treatment planning, one of the most frequently reported applications of CBCT is linear measurement of the ridge. CBCT images have been found to provide reliable bone quantity information for preoperative implant planning in different areas of the maxilla and mandible both in clinical and experimental studies ${ }^{(14-18)}$. It has been shown that magnification of CBCT-obtained linear measurements does not occur and measurements have been found to be more accurate than those obtained with medical $\mathrm{CT}^{(19,20)}$. Furthermore, dental metallic artifacts do not alter the accuracy of linear measurements obtained with $\mathrm{CBCT}^{(21)}$. Another important advantage of $\mathrm{CBCT}$ in preimplant treatment planning is the ability to evaluate the ridge topography and proximity to vital anatomical structures three dimensionally to determine whether advanced grafting is necessary for appropriate implant site development. CBCT images have proven to be superior in this regard compared with other 2D imaging modalities ${ }^{(22-25)}$.CBCT can accurately assess the thickness of cortical bone such as the facial/buccal and lingual/palatal cortical plates, the floor of the nasal cavity, and the medial and lateral walls of the maxillary sinuses.

\section{SUBJECTS AND METHODS}

\section{Patients Selection}

Twenty units dental implants , 10 Submerged superline fixtures with dual abutments(platform switched) and 10 non submerged tissue level simple line implants with dual abutments(non platform switched)were inserted in 8 patients, 4 males and 4 females with an average age 32 years (range from 22 to 43 years ) were included in this study. They were selected from the outpatient clinic of Department of Oral Medicine, Periodontology, Diagnosis and Oral Radiology, Faculty of Dental Medicine (Boys - Cairo), Al-Azhar University. Research procedures were explained to all patients, and they signed the informal consent.

\section{Inclusion criteria}

The patients who had all the inclusion criteria were selected. 1) At least 18 years old age with good oral hyegine. 2) Missing one tooth or more in the mandibular posterior region (excluding third molars), 3) Have bone density type 2 or 3 at place of surgery.

\section{Exclusion criteria}

1) History of alcohol or drug dependency, or any medical, physical, or psychological factor that might affect the surgical or prosthodontic treatment and required follow-up examinations, 2) Smokers, 3) Head and neck radiation treatment, 4) Pregnant, 5) Patient with bad oral hygiene, 6) Presence of any systemic disease affecting wound healing and success of procedures, 7) Severe bruxism or clenching habits, 8) Abnormal ridge relationships.

\section{Patient grouping:}

Patient will be randomize divided in two equal groups:

Group 1: patients will receive platform switched implants.

Group 2: patients will receive non-platform switched implants.

\section{Clinical evaluation:}

Modified plaque index (mPII) was carried out as follows:

Score 0; No detection of plaque. Score 1: Plaque only recognized by running a probe across the smooth marginal surface of the implant. Implants covered by titanium spray in this area always score 1. Score 2: Plaque can be seen by the naked eye. Score 3: Abundance of soft matter.

Modified Sulcus Bleeding Index (mBI) was carried out as follows:

Score 0: No bleeding when a periodontal probe 
is passed along the gingival margin adjacent to the implant. Score I: Isolated bleeding spots visible. Score 2: Blood forms a confluent red line on margin. Score 3: Heavy or profuse bleeding.

Both Modified plaque index(mPII) and modified Sulcus Bleeding Index (mBI) were carried out after 3, 6 and 9 months after surgery.

\section{Radiographic evaluation:}

Cone beam computed tomography (CBCT) has been carried out to evaluate buccal and lingual crestal bone changes. All radiographs for each case were taken under constant conditions. CBCT scans were carried out at baseline and 9 months postsurgically. Radiographic evaluation was established and Equalization was carefully established in both CBCT readings for every patient by adjusting focal trough at the same positions in both scans and adjusting axial, coronal and sagittal planes in fixed positions.

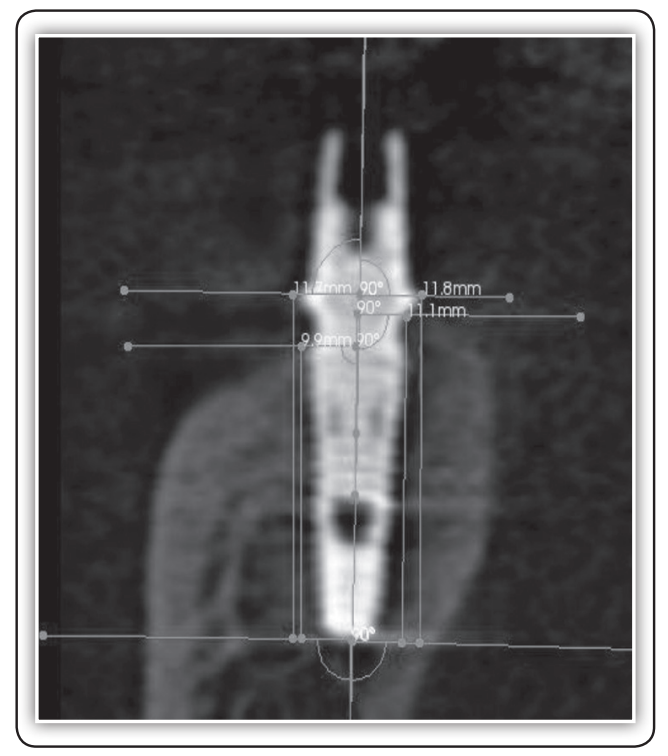

FIG (1)
Readings were obtained by drawing vertical line in the mid of implant which is the long axis line of implant, then drawing horizontal line tangent to the apex of implant which makes right angle with the long axis line, another horizontal line was drawn at fixed reference point at abutment which also is at right angle with the long axis line. Two horizontal lines at the level of crestal bone buccally and lingually were drawn at right angle to the long axis line. Two vertical lines parallel to long axis line were drawn at each side (buccal and lingual), one of them connecting the horizontal line at crestal bone with the horizontal line at implant apex and the other line was connecting the horizontal line of reference point with the horizontal line at implant apex. The shorter line was subtracted from the other line and readings were collected ${ }^{(26,27)}$. (Figure 1,2).

Measurement of crestal bone level for Measurment of crestal bone level for platform switched implant (baseline) platform switched implant (9 months)

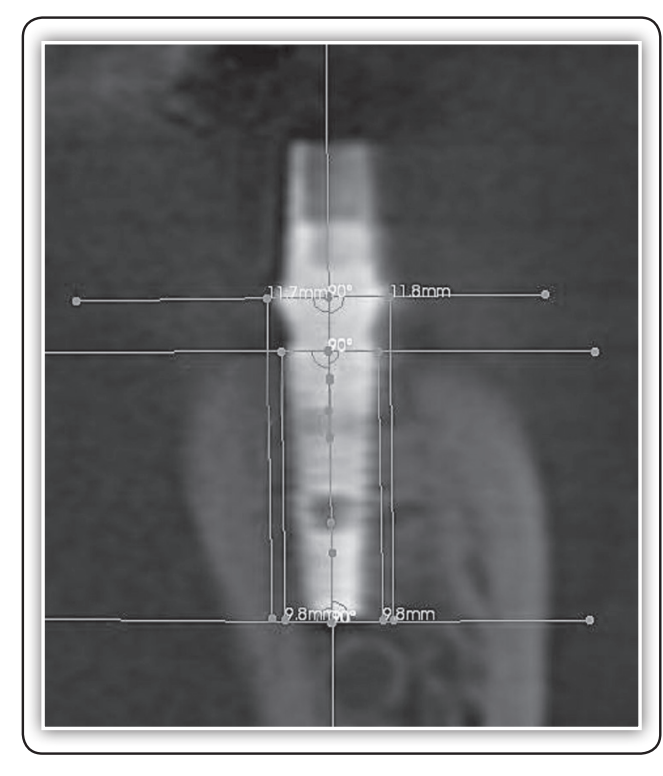

FIG (2) 


\section{RESULTS}

\section{Crestal bone loss}

Results of crestal bone loss ( $\mathrm{mm}$ ) of the two studied groups are presented in Table (1).It was evident that Group I showed Mean of $0.53 \pm 13$ while Group II showed Mean of 0.7 \pm 0.16 .

TABLE (1) Descriptive statistics of crestal bone loss (mm) after 9 months recorded from the two groups.

\begin{tabular}{|c|c|c|c|c|c|c|c|}
\hline \multirow{2}{*}{ Group } & \multirow{2}{*}{ Mean } & SD & \multirow{2}{*}{ Median } & \multirow{2}{*}{ Minimum } & \multirow{2}{*}{ Maximum } & \multicolumn{2}{|c|}{ 95\% CI } \\
\cline { 5 - 8 } & & & & & & Lower bound & Upper bound \\
\hline Group I & 0.53 & 0.13 & 0.53 & 0.40 & 0.70 & 0.40 & 0.66 \\
\hline Group II & 0.71 & 0.16 & 0.68 & 0.55 & 1.00 & 0.54 & 0.88 \\
\hline
\end{tabular}

The Comparison between the two groups showed no statistically significant difference between amounts of crestal bone loss in the two groups after 9 months (Table 2) and (Fig. 7).

TABLE (2) Mean, standard deviation (SD) values and results of Student's t-test for comparison between crestal bone loss (mm) in the two groups

\begin{tabular}{|c|c|c|c|c|}
\hline \multicolumn{2}{|c|}{ Group I } & \multicolumn{2}{c|}{ Group II } & \multirow{2}{*}{ P-value } \\
\cline { 1 - 4 } Mean & SD & Mean & SD & \\
\hline 0.53 & 0.13 & 0.71 & 0.16 & $\mathbf{0 . 0 6 1}$ \\
\hline
\end{tabular}

*: Significant at $P \leq 0.05$

\section{DISCUSSION}

It has been acknowledged that marginal bone loss is often unavoidable after implant placement, especially after the abutments are connected. In this respect the causes of marginal bone loss are complex, comprising a variety of mechanical and biologic factors ${ }^{(28)}$. Some studies postulated that microgaps at the interface between the implant platform and the abutment may contribute to its incidence ${ }^{(29,30)}$. In-vitro studies showed that microleakage occurs through these microgaps, and the degree of leakage is dependent on the type of abutment connection, the gap size, and the amount of micromovement ${ }^{(31,32)}$. In addition, the microgap permits bacterial multiplication with an open channel and then penetrate into the implant system, leading to inflammation, bone resorption and apical migration of the biologic width ${ }^{(33)}$ Standardized digital or conventional periapical radiographs were used to evaluate marginal bone loss ${ }^{(29)}$; unfortunately, they provide no information regarding buccolingual alveolar bone. Therefore, CBCT to acquire 3D images is a valuable tool to evaluate changes in the buccal alveolar bone around an implant over time. The present study applied this technique in the evaluation of the studied groups. With the advent of 3D CBCT, visualization of the bony anatomy has become possible because of the inherent accuracy of the CBCT and the clipping function, which can visualize craniofacial structures ${ }^{(34,35) \text {. }}$

In this study twenty implants were inserted in eight patients: ten implants with platform switching (PS) abutments and the others ten were performed using non platform switching(NPS) technique, these implants were clinically and radiographically evaluated, to examine crestal bone behavior with both types of implants. Clinical evaluation was carried out using modified plaque index (mPII) and modified sulcus bleeding index (mBI), Radiographic evaluation was carried out using Cone Beam CT scans at baseline and 9 months after implants insertion. The results demonstrated that the 
marginal peri-implant hard tissue changes that occurred using an implant system with platform switched abutments in comparison with another types having non platform switching were minimal and with no significance during the first 9 months after implant installation. Further, no implant failure was seen, resulting in an overall survival rate of $100 \%$.

It was evident from the obtained results that after 9 months of implant installation the mean crestal bone loss occurred in the PS implants group was $(0.53 \mathrm{~mm})$, and the other group (NPS) showed mean of $(0.71 \mathrm{~mm})$. There was no statistically significant difference between amounts of crestal bone loss in the two studied groups after 9 months. This finding agrees with many studies ${ }^{(36-42)}$. Platform switching (PS) technique was supposed to be one of the technical driven factors to achieve marginal or crestal bone stability; systematic reviews and meta-analyses supported this assumption. The effectiveness of the PS technique, significantly limiting marginal bone resorption around endosseous dental implants, while the cumulative estimated implant success rate was detected to reveal no statistically significant difference between both intervention groups of PS and non platform switching (NPS) implants ${ }^{(43)}$.

Significant differences of peri-implant marginal bone level (MBL) changes favoring the PS technique were found in five out of six randomized controlled trials (RCTs) with a follow- up period exceeding 12 months and in seven of eight RCTs with a 12-month follow-up following prosthetic loading. A single RCT reporting a follow-up of 12 months following implant insertion failed to show a significant impact of the PS technique on peri-implant marginal bone level changes ${ }^{(44)}$. Considering the results of this systematic review, only three studies indicated a peri-implant marginal bone level change significantly less in the PS groups compared to those utilizing PM implant-abutment connections. In one study, this difference was remarkable in favor of the PS group obviously, but a statistical analysis to calculate the level of significance was not performed ${ }^{(45)}$ Nevertheless, meta-analysis of
13 RCTs revealed a significantly less mean marginal bone level change at platform switched implants compared with non platform switched implants, thus confirming the supposed bone level stabilizing effect of platform switched implant-abutment configurations at least when considering shortterm observations. The longest follow-up period within the RCTs was 27 months (25 months in average $)^{(46)}$, whereas the longest follow-up period within the public communication and culture studies(PCCS) was 5 years $^{(47)}$.

It has been reported that that PS implants installed under the cortical bone level showed more significant resorption when compared with implants placed at the bone level. Additionally, a study (48) established subcrestal implants installation for both PS and NPS, with follow up 12 months. The mean marginal bone loss was $1.67 \mathrm{~mm}$ for NPS and 0.95 $\mathrm{mm}$ for PS, with statistical significance. Another study ${ }^{(49)}$ found a mean crestal bone loss for PS of 0.18 versus $2.18 \mathrm{~mm}$ when PS was not applied.

Results of the present study showed no relevant bone-protective effect of platform switching which is in agreement with other results as theses reported no differences in vertical bone-level alterations between platform switching and nonplatform switching implants could be demonstrated ${ }^{(42,50)}$. In addition these results were comparable with that of another study' showed no differences in vertical bone-level alterations between platform switching and nonplatform switching implants could be demonstrated ${ }^{(44)}$.

\section{REFERENCES}

1. John V, Chen S, Parashos P. Implant or the natural tooth?a contemporary treatment planning dilemma. Aust Dent J. 2007;52(s1):S138--S150.

2. Gardner DM. Platform switching as a means to achieving implant esthetics. N Y State Dent J. 2005;71(3):34-7.

3. Degidi M, Iezzi G, Scarano A, Piattelli A. Immediately loaded titanium implant with a tissue-stabilizing/maintaining design (beyond platform switch) retrieved from man after 4 weeks: a histological and histomorphometrical evaluation. A case report. Clin Oral Implants Res. 2008;19(3):276-82 
4. Baumgarten H, Cocchetto R, Testori T, Meltzer A, Porter $\mathrm{S}$. A new implant design for crestal bone preservation: initial observations and case report. Pract Proced Aesthetic Dent. 2005;17(10):735.

5. Rodriguez-Ciurana X, Vela-Nebot X, Segalà-Torres M, Calvo-Guirado JL, Cambra J, Méndez-Blanco V, et al. The effect of interimplant distance on the height of the interimplant bone crest when using platform-switched implants. Int J Periodontics Restorative Dent. 2009;29(2):141.

6. Porter S. Platform switching: a new concept in implant dentistry for controlling postrestorative crestal bone levels. Dent, 2006 [Internet]. [cited 2016 Mar 29]; Available from: http://biomet3i.fr/Resource Center/Articles Of Interest/PRD_26_1_2.pdf

7. Luis Calvo-Guirado J, José Ortiz-Ruiz A, Lopez-Mari L, Delgado-Ruiz R, Mate-Sanchez J, Alberto Bravo Gonzalez L. Immediate maxillary restoration of single-tooth implants using platform switching for crestal bone preservation: a 12-month study. Int J Oral Maxillofac Implants. 2009;24(2).

8. Schrotenboer J, Tsao Y-P, Kinariwala V, Wang H-L. Effect of microthreads and platform switching on crestal bone stress levels: a finite element analysis. J Periodontol. Am Acad Periodontology; 2008;79(11):2166-72.

9. Maeda Y, Miura J, Taki I, Sogo M. Biomechanical analysis on platform switching: is there any biomechanical rationale? Clin Oral Implants Res. 2007;18(5):581-4.

10. Hansson S. A conical implant--abutment interface at the level of the marginal bone improves the distribution of stresses in the supporting bone. Clin Oral Implants Res. 2003;14(3):286-93.

11. Kaur S, Khuller N, Bansal P, Bhatia A, Mehta A. Platform Switching- Preserving the Crestal Bone. J Periodontal Med Clin Pract 2015; 02:46-56. 2015;

12. Duyck J, Naert I, Rønold HJ, Ellingsen JE, Van Oosterwyck H, Vander Sloten J. The influence of static and dynamic loading on marginal bone reactions around osseointegrated implants: an animal experimental study. Clin Oral Implants Res. 2001;12(3):207-18.

13. Chang C-L, Chen C-S, Hsu M-L. Biomechanical effect of platform switching in implant dentistry: a three-dimensional finite element analysis. Int J Oral Maxillofac Implants. 2010;25(2).

14. Dreiseidler T, Neugebauer J, Ritter L, Lingohr T, Rothamel D, Mischkowski RA, et al. Accuracy of a newly developed integrated system for dental implant planning. Clin Oral Implants Res. 20(11):1191-9.
15. Madrigal C, Ortega R, Meniz C, López-Quiles J. Study of available bone for interforaminal implant treatment using cone-beam computed tomography. Med Oral Patol Oral y Cir Bucal. Medicina Oral SL; 2008;13(5):307.

16. Suomalainen A, Vehmas T, Kortesniemi M, Robinson S, Peltola J. Accuracy of linear measurements using dental cone beam and conventional multislice computed tomography. Dentomaxillofacial Radiol. British Institute of Radiology; 2014;

17. Veyre-Goulet S, Fortin T, Thierry A. Accuracy of linear measurement provided by cone beam computed tomography to assess bone quantity in the posterior maxilla: a human cadaver study. Clin Implant Dent Relat Res. 2008;10(4):226-30.

18. Shiratori LN, Marotti J, Yamanouchi J, Chilvarquer I, Contin I, Tortamano-Neto P. Measurement of buccal bone volume of dental implants by means of cone-beam computed tomography. Clin Oral Implants Res. 2012;23(7):797-804.

19. Yim J, Ryu D, Lee B, Kwon Y. Analysis of digitalized panorama and cone beam computed tomographic image distortion for the diagnosis of dental implant surgery. J Craniofac Surg. 2011;22(2):669-73.

20. Al-Ekrish AA, Ekram M. A comparative study of the accuracy and reliability of multidetector computed tomography and cone beam computed tomography in the assessment of dental implant site dimensions. Dentomaxillofacial Radiol. The British Institute of Radiology. 36 Portland Place, London, W1B 1AT; 2014;

21. Cremonini CC, Dumas M, Pannuti CM, Neto JBC, Cavalcanti MGP, Lima LA. Assessment of linear measurements of bone for implant sites in the presence of metallic artefacts using cone beam computed tomography and multislice computed tomography. Int J Oral Maxillofac Surg. 2011;40(8):845-50.

22. Angelopoulos C, Thomas S, Hechler S, Parissis N, Hlavacek M. Comparison between digital panoramic radiography and cone-beam computed tomography for the identification of the mandibular canal as part of presurgical dental implant assessment. J Oral Maxillofac Surg. 008;66(10):2130-5.

23. Bornstein MM, Balsiger R, Sendi P, von Arx T. Morphology of the nasopalatine canal and dental implant surgery: a radiographic analysis of 100 consecutive patients using limited cone-beam computed tomography. Clin Oral Implants Res. 2011;22(3):295-301. 
24. Chan H-L, Brooks SL, Fu J-H, Yeh C-Y, Rudek I, Wang $\mathrm{H}-\mathrm{L}$. Cross-sectional analysis of the mandibular lingual concavity using cone beam computed tomography. Clin Oral Implants Res. 2011;22(2):201-6.

25. Lofthag-Hansen S, Gröndahl K, Ekestubbe A. Cone-Beam CT for Preoperative Implant Planning in the Posterior Mandible: Visibility of Anatomic Landmarks. Clin Implant Dent Relat Res. 2009;11(3):246-55.

26. Kook Y, Kim G, Kim Y. Comparison of alveolar bone loss around incisors in normal occlusion samples and surgical skeletal Class III patients. 2012;82(4).

27. Vera C, De Kok IJ, Reinhold D, Limpiphipatanakorn P, Yap AKW, Tyndall D, et al. Evaluation of buccal alveolar bone dimension of maxillary anterior and premolar teeth: a cone beam computed tomography investigation. Int J Oral Maxillofac Implants. 2012;27(6).

28. Oh T-J, Yoon J, Misch CE, Wang H-L. The causes of early implant bone loss: myth or science? J Periodontol. Am Acad Periodontology; 2002;73(3):322-33.

29. Cochran DL, Nummikoski P V, Schoolfield JD, Jones AA, Oates TW. A prospective multicenter 5-year radiographic evaluation of crestal bone levels over time in 596 dental implants placed in 192 patients. J Periodontol. Am Acad Periodontology; 2009;80(5):725-33.

30. Hermann JS, Schoolfield JD, Schenk RK, Buser D, Cochran DL. Influence of the size of the microgap on crestal bone changes around titanium implants. A histometric evaluation of unloaded non-submerged implants in the canine mandible. J Periodontol. Am Acad Periodontology; 2001;72(10):1372-83.

31. Steinebrunner L, Wolfart S, Bößmann K, Kern M. In vitro evaluation of bacterial leakage along the implant-abutment interface of different implant systems. Int J Oral Maxillofac Implants. 2005;20(6).

32. Tesmer M, Wallet S, Koutouzis T, Lundgren T. Bacterial colonization of the dental implant fixture-abutment interface: an in vitro study. J Periodontol. Am Acad Periodontology; 2009;80(12):1991-7.

33. Abrahamsson I, Berglundh T, Wennström J, Lindhe J. The peri-implant hard and soft tissues at different implant systems. A comparative study in the dog. Clin Oral Implants Res. 1996;7(3):212-9.

34. Weinberg SM, Kolar JC. Three-dimensional surface imaging: limitations and considerations from the anthropometric perspective. J Craniofac Surg. 2005;16(5):847-51.
35. Mah J, Hatcher D. Current status and future needs in craniofacial imaging. Orthod Craniofac Res. Wiley Online Library; 2003;6(s1):10-6.

36. Schrotenboer J, Tsao Y-P, Kinariwala V, Wang H-L. Effect of platform switching on implant crest bone stress: a finite element analysis. Implant Dent. 2009;18(3):260-9.

37. Enkling N, Boslau V, Klimberg T, Jöhren P, Deserno T, Mericske-Stern R, et al. Platform switching: A randomized clinical trial--One year results. J Dent Res. 2009;88(special issue A):3394.

38. Dursun E, Tulunoglu I, Canplinar P, Uysal S, Akallin FA, Tözüm TF. Are marginal bone levels and implant stability/ mobility affected by single-stage platform switched dental implants? A comparative clinical study. Clin Oral Implants Res. 2012;23(10):1161-7.

39. Canay S, Akça K. Biomechanical aspects of bone-level diameter shifting at implant-abutment interface. Implant Dent. 2009;18(3):239-48.

40. Becker J, Ferrari D, Herten M, Kirsch A, Schaer A, Schwarz F. Influence of platform switching on crestal bone changes at non-submerged titanium implants: a histomorphometrical study in dogs. J Clin Periodontol. 2007;34(12):1089-96.

41. Linkevicius T, Apse P, Grybauskas S, Puisys A. Influence of thin mucosal tissues on crestal bone stability around implants with platform switching: a 1-year pilot study. J Oral Maxillofac Surg. 2010;68(9):2272-7.

42. Becker J, Ferrari D, Mihatovic I, Sahm N, Schaer A, Schwarz F. Stability of crestal bone level at platform-switched nonsubmerged titanium implants: a histomorphometrical study in dogs. J Clin Periodontol. 2009; 36(6):532-9.

43. Atieh MA, Ibrahim HM, Atieh AH. Platform switching for marginal bone preservation around dental implants: a systematic review and meta-analysis. J Periodontol. Am Acad Periodontology; 2010;81(10):1350-66.

44. Enkling N, Jöhren P, Klimberg V, Bayer S, Mericske-Stern $\mathrm{R}$, Jepsen S. Effect of platform switching on peri-implant bone levels: a randomized clinical trial. Clin Oral Implants Res. 2011;22(10):1185-92.

45. de Almeida FD, Carvalho ACP, Fontes M, Pedrosa A, Costa R, Noleto JW, et al. Radiographic evaluation of marginal bone level around internal-hex implants with switched platform: a clinical case report series. Int J Oral Maxillofac Implants. 2011;26(3).

46. Canullo L, Goglia G, Iurlaro G, Iannello G. Short-term bone level observations associated with platform switching 
in immediately placed and restored single maxillary implants: a preliminary report. Int J Prosthodont. 2009;22(3).

47. Vigolo P, Givani A. Platform-switched restorations on wide-diameter implants: a 5-year clinical prospective study. Int J Oral Maxillofac Implants. 2009;24(1).

48. Cappiello M, Luongo R, Di Iorio D, Bugea C, Cocchetto R, Celletti R. Evaluation of peri-implant bone loss around platform-switched implants. Int J Periodontics Restorative Dent. 2008;28(4).

49. Buser D, Wittneben J, Bornstein MM, Grütter L, Chap- puis V, Belser UC. Stability of contour augmentation and esthetic outcomes of implant-supported single crowns in the esthetic zone: 3-year results of a prospective study with early implant placement postextraction. J Periodontol. Am Acad Periodontology; 2011;82(3):342-9.

50. Weng D, Nagata MJH, Bell M, Bosco AF, De Melo LGN, Richter E-J. Influence of microgap location and configuration on the periimplant bone morphology in submerged implants. An experimental study in dogs. Clin Oral Implants Res. 2008;19(11):1141-7. 